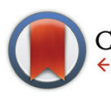

CrossMark

Cite this: Polym. Chem., 2017, 8, 451

\section{A biocompatible macromolecular two-photon initiator based on hyaluronan $\dagger$}

\author{
Maximilian Tromayer, ${ }^{\mathrm{a}, \mathrm{e}}$ Peter Gruber, ${ }^{\mathrm{b}, \mathrm{e}}$ Marica Markovic, ${ }^{\mathrm{b}, \mathrm{e}}$ Arnulf Rosspeintner, ${ }^{\mathrm{c}}$ \\ Eric Vauthey, ${ }^{c}$ Heinz Redl, ${ }^{\text {d,e }}$ Aleksandr Ovsianikov ${ }^{\text {bee }}$ and Robert Liska ${ }^{a, e}$
}

Received 12th October 2016 Accepted 21st November 2016 DOI: $10.1039 /$ c6py01787h www.rsc.org/polymers

\begin{abstract}
The possibility of the direct encapsulation of living cells via two-photon induced photopolymerization enables the microfabrication of hydrogel scaffolds with high initial cell loadings and intimate matrix-cell contact. While highly efficient water-soluble two-photon initiators based on benzylidene ketone dyes have been developed, they exhibit considerable cyto- and phototoxicity. To address the problem of photoinitiator migration from the extracellular matrix into the cytosol, a two-photon initiator bound to a polymeric hyaluronan backbone (HAPI) was synthesized in this work. HAPI exhibited a distinct improvement of cytocompatibility compared to a reference two-photon initiator. Basic photophysical investigations were performed to characterize the absorption and fluorescence behavior of HAPI. Laser scanning microscopy was used to visualize and confirm the hindered transmembrane migration behavior of HAPI. The performance of HAPI was tested in two-photon polymerization at exceedingly high printing speeds of $100 \mathrm{~mm} \mathrm{~s}^{-1}$ producing gelatin-based complex 3D hydrogel scaffolds with a water content of $85 \%$. The photodamage of the structuring process was low and viable MC3T3 cells embedded in the gel were monitored for several days after structuring.
\end{abstract}

\section{Introduction}

The process of two-photon induced polymerization (2PP) has attracted considerable interest because it enables 3D printing with a resolution in the sub-micrometer range. Parts containing ultra-small features like photonic crystals, cantilevers, optical waveguides and microelectronic components may thus be produced. ${ }^{1}$ Furthermore $2 \mathrm{PP}$ can be employed to fabricate 3D scaffolds as a structural support for cell growth in tissue engineering. ${ }^{2}$ This is of great interest because $2 \mathrm{D}$ matrices used in traditional cell culture systems do not accurately reproduce the cells' natural environment and lead to significant differences in the structure, function or physiology compared to living tissue. Various studies ${ }^{3,4}$ have investigated and demonstrated that 3D-matrix adhesions enhanced cellular functional activities compared to $2 \mathrm{D}$ adhesions. Bokhari et al.

\footnotetext{
${ }^{a}$ Institute of Applied Synthetic Chemistry, TU Wien (Technische Universitaet Wien), Getreidemarkt 9/163/MC, 1060 Vienna, Austria

${ }^{b}$ Institute of Materials Science and Technology, TU Wien (Technische Universitaet Wien), Getreidemarkt 9/308, 1060 Vienna, Austria

${ }^{c}$ Physical Chemistry Department, Sciences II, University of Geneva, 30 Quai Ernest Ansermet, CH-1211 Geneva 4, Switzerland

${ }^{d}$ Ludwig Boltzmann Institute - Experimental and Clinical Traumatology, Donaueschingenstraße 13, 1200 Vienna, Austria

${ }^{e}$ Austrian Cluster for Tissue Regeneration, Austria

$\dagger$ Electronic supplementary information (ESI) available. See DOI: 10.1039/ c6py01787h
}

have shown that HepG2 hepatocytes grown on 3D polystyrene scaffolds are less susceptible to certain toxicological challenges than those grown in $2 \mathrm{D} .^{3}$

Usually such scaffolds are pre-fabricated with large enough pores and seeded with cells on the surface, which then migrate inside the scaffold, attach within the pores and proliferate there. Another popular approach is the encapsulation of cells within hydrogels, which can be cross-linked by different means, including photopolymerization. Cell encapsulation provides the advantages of high initial cell loading and more intimate cell-matrix contact, similar to that of the natural extracellular matrix (ECM).

Since biological tissue is relatively transparent at the laser wavelengths used for $2 \mathrm{PP}$, arbitrary $3 \mathrm{D}$ structures can be created deep within aqueous media. Thus $2 \mathrm{PP}$ can in principle be employed to encapsulate living cells within 3D hydrogel structures by performing $2 \mathrm{PP}$ around them. ${ }^{5}$

Recently several specialized water-soluble two photon initiators (2PIs) have been developed and tested for their efficiency in the microfabrication of 3D hydrogel structures. ${ }^{6}$ While they possess a relatively high two-photon absorption (2PA) cross section compared to commercial water-soluble one-photon initiators like Irgacure 2959, and thus allow for structuring at high printing speeds and low laser intensities, there is still a need for novel initiators with improved cytocompatibility. Besides the mere cytotoxicity in darkness, the occurrence of additional phototoxicity upon irradiation is an 
important concern with PIs designed for biological applications.

The aforementioned phototoxicity can either be mediated by the active species that are generated from the PI itself, i.e. free radicals in the case of initiators for radical photopolymerization, or by other species that originate from secondary pathways. Among the non-radiative processes that lead to the relaxation of the involved excited triplet states of the PI, quenching by molecular oxygen under the formation of singlet oxygen (SO) and as a further consequence other reactive oxygen species (ROS) play an important role. Oxygen-activated species such as superoxide anions, hydroxyl radicals and singlet oxygen are by-products of oxygen-dependent reactions and have a wide potential for causing cell damage. Among these chemical entities, singlet oxygen is one of the most reactive, capable of damaging cells and tissues. Besides its relatively long lifetime in solution, from micro- to milliseconds, singlet oxygen behaves as a strong electrophile in solution and reacts avidly with molecules possessing regions of high electron density. The oxidative damage of cells mediated by singlet oxygen is common and DNA, proteins and lipids are all at risk. ${ }^{7}$ In fact, this is also made use of for medical purposes in photodynamic therapy. ${ }^{8}$ In the case of the encapsulation of living cells via 2PP using water soluble 2PIs, it is hypothesized that due to their size and low molecular weight, they are able to pass the cytoplasmic membrane and migrate inside the cells. Since the cells are highly transparent for the lasers used in 2PP, the 2PI molecules are excited within the cytoplasm and the generated radicals and ROS may damage vital structures inside the cells. Thus, limiting the diffusion of 2PIs through the cell membrane might be an efficient strategy to reduce the overall photodamage to the cells and tackle the problem of phototoxicity of the 2PP structuring process.

A promising approach designing molecules to realize this is increasing the size and molecular weight of the 2PI by modifying a polymeric backbone, covalently attaching several units of a suitable derivative based on a previously examined efficient low molecular weight 2PI.

Hyaluronan (HA) was chosen as a backbone for novel polymeric 2PIs in this present work. HA is a natural and vital part of the $\mathrm{ECM}^{9}$ and is becoming increasingly important as a building block for the creation of new bio-materials with utility in tissue engineering and regenerative medicine. ${ }^{10-12}$ Furthermore there are suitable methods for chemical modification $e . g$. amidation, ${ }^{13,14}$ and it is a highly negatively charged polycarboxylate, which poses an additional hindrance to migration through the cytoplasmic membrane which also bears a net negative charge. ${ }^{15}$

Two recent publications describe the synthesis and application of several efficient 2PIs based on cyclic dibenzylidene ketones - the first one ${ }^{16}$ focuses on 2PIs intended for polymerizable formulations based on organic solvents and resins, while the second one ${ }^{6}$ discusses derivatives bearing carboxylgroups linked to their amino donor-functionalities leading to water-solubility and thus extending the range of application to hydrogel-based materials. Since the water solubility is already<smiles>CN(C)c1ccc(/C=C2\CC(N)C/C(=C\c3ccc(N(C)C)cc3)C2=O)cc1</smiles>

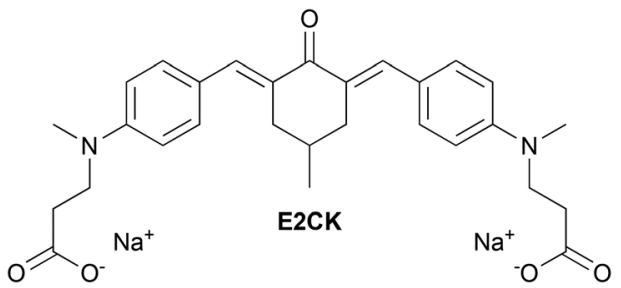

Fig. 1 Precursor MCNK and reference E2CK, an efficient low molecular water-soluble $2 \mathrm{PI}$.

provided by the polycarboxylate HA-backbone and additional carboxyl groups in the 2PIs would only make the synthesis and purification more difficult, the 2PI component should bear simple alkylamino-groups that provide good organo-solubility until the last step of coupling to HA.

It has been reported in the literature that the quantum yield of singlet oxygen production from excited cyclic dibenzylidene ketones depends strongly on the size of the central ring, decreasing drastically for larger ring sizes in a series of cyclobutanone, cyclopentanone and cyclohexanone based derivatives. $^{17}$

Because of the prospect of lower phototoxicity for a sixmembered central ring, the high initiation efficiency previously reported for similar derivatives, ${ }^{6,16}$ several successful reports of amidations of HA in the literature using 1,1'-carbonyldiimidazole (CDI $)^{14,18-20}$ as well as commercial availability of suitable starting materials, the 2PI in this work was based on an amino substituted cyclohexanone. Fig. 1 shows the basic structure of the amino-cyclohexanone 2PI MCNK prepared in this work, and the previously published ${ }^{6}$ cyclohexanone based reference 2PI E2CK.

After linking MCNK to HA, the complete polymer-bound 2PI was characterized by various spectroscopic methods, tested for cytotoxicity in darkness and finally applied in the 2PP encapsulation of living cells.

\section{Experimental}

\section{Materials and methods}

Chemicals. Hyaluronan (hyaluronic acid sodium salt from Streptococcus equi, bacterial glycosaminoglycan polysaccharide), (4-oxocyclohexyl)carbamic acid tert-butyl ester (Boc-CNK), 4-(tert-butoxycarbonylamino)butyric acid (Boc-GABA-OH), 4-dimethylamino benzaldehyde and methyl- $\beta$-cyclodextrin (MBCD, BioReagent grade, 1.5-2.1 methyl per mol glucose) were purchased from Sigma-Aldrich and used without further purifi- 
cation. Solvents and other reagents were purchased from Sigma Aldrich, Fluka, Merck and Riedel-de Haen and were either used without further purification or dried and purified by standard laboratory methods.

Mode of practice for photosensitive compounds. The preparation and analysis of the photosensitive compounds and formulations was conducted in an orange light lab. The windows and fluorescent lamps were covered with a foil filter or filter coatings so that light with a wavelength $<520 \mathrm{~nm}$ was cut off.

Melting point (mp), HR-MS, pH, gel permeation chromatography analyses. Melting points were measured with the aid of an automated melting point system (SRS OptiMelt MPA100). An Agilent 6230 LC TOFMS mass spectrometer equipped with an Agilent Dual AJS ESI source was used for HR-MS analysis. pH-Values were determined with a WTW pH 340i pocket meter. Molecular weights $\left(M_{\mathrm{n}}\right)$ of HA before and after acidic degradation were determined by gel permeation chromatography using a Viscotek GPCmax VE 2001 with a VE 3580 RI detector calibrated with Shodex P-82 pullulan standards.

Nuclear magnetic resonance (NMR) spectroscopy. ${ }^{1} \mathrm{H}-\mathrm{NMR}$ $\left(200 \mathrm{MHz}\right.$ ) and ${ }^{13} \mathrm{C}-\mathrm{NMR}(50 \mathrm{MHz})$ spectra were recorded with a BRUKER AC-E 200 FT-NMR-spectrometer. The chemical shift ( $\mathrm{s}=$ singlet, $\mathrm{bs}=$ broad singlet, $\mathrm{d}=$ doublet, $\mathrm{t}=$ triplet, $\mathrm{m}=$ multiplet) is displayed in ppm using the non-deuterated solvent as the internal standard. Solvents with a grade of deuteration of at least $99.5 \%$ were used and purchased from EURISOTOP.

\section{Syntheses of precursors and the polymer-based two-photon-} initiator (HAPI)

Synthesis of $(3 E, 5 E)-N$-[3,5-bis[[4-(dimethylamino)phenyl] methylene]-4-oxocyclohexyl]carbamic acid 1,1-dimethylethyl ester (Boc-MCNK). To a stirred solution of Boc-CNK (715 mg, $3.35 \mathrm{mmol}$ ) in ethanol ( $5 \mathrm{~mL})$, a solution of 4 -(dimethylamino) benzaldehyde (1 g, $6.70 \mathrm{mmol}$ ) and potassium hydroxide (188 $\mathrm{mg}, 3.35 \mathrm{mmol}$ ) in ethanol $(5 \mathrm{~mL})$ was added. The reaction mixture was heated to $60{ }^{\circ} \mathrm{C}$ and stirred for $18 \mathrm{~h}$. After cooling, the resulting orange precipitate was recovered by suction filtration, washed with cold ethanol and dried in vacuo.

Yield: $1.12 \mathrm{~g}$ (70\% of theory).

Mp: $219-222^{\circ} \mathrm{C}$.

HR-MS $m / z:[\mathrm{M}+\mathrm{H}]^{+}$calculated for $\mathrm{C}_{29} \mathrm{H}_{38} \mathrm{~N}_{3} \mathrm{O}_{3}$ 476.2908; found 476.2932.

${ }^{1} \mathrm{H}$ NMR (200 MHz, $\left.\mathrm{CDCl}_{3}\right): \delta(\mathrm{ppm})=7.88(2 \mathrm{H}, \mathrm{s}), 7.42(4 \mathrm{H}$, $\mathrm{d}, J=8.9 \mathrm{~Hz}), 6.69(4 \mathrm{H}, \mathrm{d}, J=8.9 \mathrm{~Hz}), 4.58-4.90(1 \mathrm{H}, \mathrm{m}), 4.09$ (1H, bs), 2.72-3.25 (16H, m), 1.37 (9H, s).

${ }^{13} \mathrm{C} \mathrm{NMR}\left(50 \mathrm{MHz}, \mathrm{CDCl}_{3}\right): \delta(\mathrm{ppm})=188.3,155.1,150.6$, 139.9, 132.6, 128.1, 123.6, 111.6, 79.3, 45.2, 40.1, 34.4, 28.4.

Synthesis of $(2 E, 6 E)$-4-amino-2,6-bis[[4-(dimethylamino) phenyl]methylene]cyclohexanone (MCNK). Phosphoric acid ( $85 \%$ aqueous solution, $2 \mathrm{~mL}$ ) was added to a suspension of Boc-MCNK (875 mg, $1.84 \mathrm{mmol}$ ) in dichloromethane $(7.5 \mathrm{~mL}$ ) and stirred vigorously to ensure constant mixing of the phases. After $3 \mathrm{~h}$ of stirring at ambient temperature, the solids had dissolved resulting in an almost colorless organic phase and a bluish grey aqueous phase. Deionized water $(25 \mathrm{~mL})$ was added, the reaction mixture cooled to $0{ }^{\circ} \mathrm{C}$ and sodium hydroxide (50\% aqueous solution) was added drop-wise to bring the aqueous phase to $\mathrm{pH} \sim 9$. The aqueous phase was extracted with dichloromethane $(3 \times 75 \mathrm{~mL})$, adding more water as necessary to dissolve the remaining solid phosphate salts. The combined organic layers were dried over $\mathrm{Na}_{2} \mathrm{SO}_{4}$ and stripped of the solvent in vacuo, resulting in orange flakes.

Yield: $656 \mathrm{mg}$ (95\% of theory).

Mp: $158-160{ }^{\circ} \mathrm{C}$.

HR-MS m/z: $[\mathrm{M}+\mathrm{H}]^{+}$calculated for $\mathrm{C}_{24} \mathrm{H}_{30} \mathrm{~N}_{3} \mathrm{O}$ 376.2383; found 376.2394 .

${ }^{1} \mathrm{H}$ NMR $\left(200 \mathrm{MHz}, \mathrm{CDCl}_{3}\right): \delta(\mathrm{ppm})=7.82(2 \mathrm{H}, \mathrm{s}), 7.43(4 \mathrm{H}$, $\mathrm{d}, J=9.0 \mathrm{~Hz}), 6.69(4 \mathrm{H}, \mathrm{d}, J=9.0 \mathrm{~Hz}), 3.10-3.30(3 \mathrm{H}, \mathrm{m}), 3.00$ (12H, s), 2.55-2.83 (2H, m), 1.39 (2H, s).

${ }^{13} \mathrm{C} \mathrm{NMR}\left(50 \mathrm{MHz}, \mathrm{CDCl}_{3}\right): \delta(\mathrm{ppm})=188.8,150.5,138.5$, 132.5, 129.6, 123.9, 111.6, 47.0, 40.1, 38.1.

Synthesis of $(3 E, 5 E)-N$-[4-[[3,5-bis[[4-(dimethylamino)phenyl $]$ methylene]-4-oxocyclohexyl]amino]-4-oxobutyl]carbamic acid 1,1-dimethylethyl ester (Boc-MGABA). Boc-GABA-OH (300 mg, $1.48 \mathrm{mmol}$ ) and CDI (239 $\mathrm{mg}, 1.48 \mathrm{mmol}$ ) were dissolved in anhydrous dichloromethane $(3 \mathrm{~mL})$ and stirred for $20 \mathrm{~min}$ after cessation of the initial gas formation. A suspension of MCNK (556 mg, $1.48 \mathrm{mmol}$ ) in dichloromethane $(10 \mathrm{~mL})$ was added and the resulting mixture was stirred for $18 \mathrm{~h}$. After removal of the solvent in vacuo, the solid residue was recrystallized from ethyl acetate.

Yield: $830 \mathrm{mg}$ (79\% of theory).

Mp: decomposition $>250{ }^{\circ} \mathrm{C}$.

HR-MS m/z: $[\mathrm{M}+\mathrm{H}]^{+}$calculated for $\mathrm{C}_{33} \mathrm{H}_{45} \mathrm{~N}_{4} \mathrm{O}_{4}$ 561.3435; found 561.3461 .

${ }^{1} \mathrm{H}$ NMR $\left(200 \mathrm{MHz}, \mathrm{CDCl}_{3}\right): \delta(\mathrm{ppm})=7.85(2 \mathrm{H}, \mathrm{s}), 7.37(4 \mathrm{H}$, $\mathrm{d}, J=8.9 \mathrm{~Hz}), 6.64(4 \mathrm{H}, \mathrm{d}, J=8.9 \mathrm{~Hz}), 6.49(1 \mathrm{H}, \mathrm{d}, J=7.0 \mathrm{~Hz})$, 4.86 (1H, bs), 4.25-4.49 (1H, m), 2.90-3.22 (18H, m), $2.13(2 \mathrm{H}$, $\mathrm{t}, J=7.0 \mathrm{~Hz}), 1.70(2 \mathrm{H}$, quin, $J=6.8 \mathrm{~Hz}), 1.40(9 \mathrm{H}, \mathrm{s})$.

${ }^{13} \mathrm{C} \mathrm{NMR}\left(50 \mathrm{MHz}, \mathrm{CDCl}_{3}\right): \delta(\mathrm{ppm})=188.3,172.1,156.3$, 150.6, 140.1, 132.7, 127.9, 123.5, 111.7, 79.1, 44.2, 40.1, 39.7, $33.9,33.6,28.4,26.2$.

Synthesis of $(3 E, 5 E)$-4-amino- $N$-[3,5-bis[[4-(dimethylamino) phenyl]methylene]-4-oxocyclohexyl]butanamide (MGABA). The deprotection of Boc-MGABA to obtain MGABA was carried out in analogy to the synthesis of MCNK.

Yield 94\%.

Mp: $146-148^{\circ} \mathrm{C}$.

HR-MS $m / z:[\mathrm{M}+\mathrm{H}]^{+}$calculated for $\mathrm{C}_{28} \mathrm{H}_{37} \mathrm{~N}_{4} \mathrm{O}_{2}$ 461.2911; found 461.2919.

${ }^{1} \mathrm{H}$ NMR $\left(200 \mathrm{MHz}, \mathrm{CDCl}_{3}\right): \delta(\mathrm{ppm})=7.85(2 \mathrm{H}, \mathrm{s}), 7.36(4 \mathrm{H}$, $\mathrm{d}, J=8.8 \mathrm{~Hz}), 6.74(1 \mathrm{H}, \mathrm{d}, J=7.8 \mathrm{~Hz}), 6.63(4 \mathrm{H}, \mathrm{d}, J=8.8 \mathrm{~Hz})$, 4.27-4.48 $(1 \mathrm{H}, \mathrm{m}, J=4.7$ and 4.7 and $7.8 \mathrm{~Hz}), 3.06(4 \mathrm{H}, \mathrm{d}, J=$ $4.7 \mathrm{~Hz}), 2.97(12 \mathrm{H}, \mathrm{s}), 2.57(2 \mathrm{H}, \mathrm{t}, J=7.0 \mathrm{~Hz}), 2.14(2 \mathrm{H}, \mathrm{t}, J=$ $7.2 \mathrm{~Hz}), 1.62(2 \mathrm{H}$, quin, $J=7.0 \mathrm{~Hz}), 1.31(2 \mathrm{H}, \mathrm{s})$.

${ }^{13} \mathrm{C} \mathrm{NMR}\left(50 \mathrm{MHz}, \mathrm{CDCl}_{3}\right): \delta(\mathrm{ppm})=188.3,172.5,150.6$, $140.1,132.7,127.9,123.4,111.6,43.8,41.4$, 40.0, 34.2, 33.7, 29.0.

Synthesis of hyaluronan-based photoinitiator (HAPI). For low molecular weight HAPI, sodium hyaluronate (1.5 g, 
1.6 $\mathrm{MDa}$ ) was degraded by dissolving in deionized water $(150 \mathrm{~mL})$, adjusting to $\mathrm{pH} 1.00$ with conc. $\mathrm{HCl}$ and by mechanical stirring at $60{ }^{\circ} \mathrm{C}$ for $24 \mathrm{~h}$. After cooling down to room temperature and adjusting to $\mathrm{pH} 7.00-7.05$ with TBA-OH (1 M in $\mathrm{MeOH}$ ), the reaction mixture was stirred for $1 \mathrm{~h}$ and the white precipitate that formed was removed by centrifugation. The resulting clear solution was dialyzed against deionized water to remove small oligomers and excess TBA-Cl. Freezedrying afforded $1.22 \mathrm{~g}$ tetrabutyl ammonium hyaluronate (TBA-HA) as a white fibrous solid.

An aliquot of TBA-HA (125 mg, $200 \mu \mathrm{mol} H A$ repetition units) was dissolved in dry DMSO $(12 \mathrm{~mL})$ under an argon atmosphere. After the addition of CDI $(9.8 \mathrm{mg}, 60 \mu \mathrm{mol})$ and methanesulfonic acid (1.46 mg, $15 \mu \mathrm{mol})$ stirring was continued for $18 \mathrm{~h}$, then MGABA $(55.6 \mathrm{mg}, 120 \mu \mathrm{mol})$ was added and the clear orange solution was stirred for another $72 \mathrm{~h}$. Brine $(1.2 \mathrm{~mL})$ was added dropwise to the reaction mixture and after $2 \mathrm{~h}$ of stirring at ambient temperature, acetone $(35 \mathrm{~mL})$ was added. The resulting orange precipitate was separated by centrifugation and washed with acetone $(3 \times 45 \mathrm{~mL})$ by stirring vigorously and subsequent centrifugation. The precipitate was then dissolved in deionized water $(25 \mathrm{~mL})$, the resulting red solution dialyzed against deionized water and freeze-dried to obtain HAPI as a bright orange fibrous solid.

Yields: degradation step - $1.22 \mathrm{~g}$ ( $81 \%$ of theory), modification step $-83 \mathrm{mg}$ ( $95 \%$ of theory).

$M_{\mathrm{n}}$ (GPC of TBA-HA, $24 \mathrm{~h}$ degradation time): $50 \mathrm{kDa}$.

${ }^{1} \mathrm{H}$ NMR $\left(200 \mathrm{MHz}, \mathrm{D}_{2} \mathrm{O}\right)$ of HAPI: $\delta(\mathrm{ppm})=7.57(0.19 \mathrm{H}$ [varies with DS], bs), 7.01-7.45 (0.40H [varies with DS], m), 6.28-6.86 (0.39H [varies with DS], m), 4.19-4.64 (2H, m), 3.17-4.02 (10H, m), 2.52-3.03 (1.70 H [varies with DS], m), 1.92 (3H, bs).

\section{Photophysics}

Absorption spectra were recorded on a Cary 50 absorption spectrometer. Fluorescence spectra were recorded on a Jobin Yvon FluoroMax-4. The fluorescence spectra were corrected for the wavelength dependent sensitivity of the apparatus using a set of secondary emissive standards. ${ }^{21}$ The samples were measured in PBS-buffer (Roti-Cell, Roth). Emission quantum yields were determined using Rhodamine $6 \mathrm{G}$ in methanol as the reference $\left(\phi_{\mathrm{r}}=0.95\right)$ according to

$$
\phi_{\mathrm{s}}=\phi_{\mathrm{r}}\left(\frac{n_{\mathrm{s}}^{2}}{n_{\mathrm{r}}^{2}}\right)\left(\frac{I_{\mathrm{s}}}{I_{\mathrm{r}}}\right)\left(\frac{A_{\mathrm{r}} \times 10^{-d_{\mathrm{eff}} \cdot A_{\mathrm{r}}}}{A_{\mathrm{s}} \times 10^{-d_{\mathrm{eff}} \cdot A_{\mathrm{s}}}}\right) .
$$

Here, $n_{x}, I_{x}$ and $A_{x}$ are the refractive index, integrated emission intensity and absorbance at the excitation wavelength of $x$, with $x$ being either the sample or reference. For the samples with quantum yields below $1 \%$, the spectra were fitted with a lognorm function and the integral of the latter was used as $I_{\mathrm{S}}$.

Time resolved fluorescence experiments with an instrument response function of 200 ps were performed using a homebuilt single photon counting set-up, with excitation at $470 \mathrm{~nm}$ (LDH-P-C 470, PicoQuant), described in ref. 22.
Two-photon cross sections were determined via two-photon excitation spectra using a set-up similar to the one described in ref. 23 and detailed in ref. 24.

The two-photon cross section at a given wavelength, $\delta_{\mathrm{s}}^{(2)}(\lambda)$, was calculated as follows ${ }^{23}$

$$
\delta_{\mathrm{s}}^{(2)}(\lambda)=\frac{I_{\mathrm{s}}\left(\lambda, \lambda_{\mathrm{obs}}\right) c_{\mathrm{r}} \phi_{\mathrm{r}}\left(\lambda_{\mathrm{obs}}\right)}{I_{\mathrm{r}}\left(\lambda, \lambda_{\mathrm{obs}}\right) c_{\mathrm{s}} \phi_{\mathrm{s}}\left(\lambda_{\mathrm{obs}}\right)} \delta_{\mathrm{r}}^{(2)}(\lambda) .
$$

Here $I_{x}\left(\lambda, \lambda_{\text {obs }}\right)$ is the (two-photon induced) fluorescence intensity at excitation wavelength $\lambda$ and observation wavelength $\lambda_{\text {obs }}$ for either sample or reference $(x \in\{\mathrm{s}, \mathrm{r}\}) . c_{x}$ and $\phi_{x}\left(\lambda_{\text {obs }}\right)$ are the concentration and differential fluorescence quantum yield (at the observation wavelength) of the sample and reference. Rhodamine $6 \mathrm{G}$ in methanol was used as the reference for determining the absolute two-photon cross sections, while Coumarin 120 in ethanol, Coumarin 153 in methanol and LDS 698 in chloroform, were additionally used for assigning the bandshape. $^{25}$

\section{Cell culture}

Mouse calvaria-derived preosteoblast cells (MC3T3-E1 Subclone 4) were obtained from ATCC-LGC Standards. MC3T3 were expanded in Alpha Minimum Essential Medium ( $\alpha M E M)$ with ribonucleases, deoxyribonucleases, $2 \mathrm{mM}$ L-glutamine, without ascorbic acid (Gibco), supplemented with $10 \%$ fetal bovine serum (Sigma) and $1 \%$ of $10000 \mathrm{U} \mathrm{mL}^{-1}$ penicillin/ streptomycin (Lonza). The cells were cultivated in an incubator in a humid atmosphere with $5 \%$ carbon dioxide at $37{ }^{\circ} \mathrm{C}$. The medium was refreshed every second day.

\section{Evaluation of photoinitiator cytocompatibility}

To evaluate the cytocompatibility of photoinitiators, PrestoBlue Cell Viability Reagent (Life Technologies) was used. For these tests 96-well plates were seeded with 5000 cells per well and incubated overnight for cells to attach. The cells were incubated with $100 \mu \mathrm{L}$ of different dilutions of 2.0, 1.0 and $0.5 \mathrm{mM}$ solutions of HAPI and E2CK for comparison. The procedure was performed under red light (620 nm LED) because of the light sensitivity and potential additional phototoxicity of the 2PIs. After $5 \mathrm{~h}$ of incubation with 2PIs, the culture medium was exchanged twice to remove 2 PI residues and cell viability was evaluated. The resazurin-based reagent PrestoBlue was diluted 1:10 with the medium and $100 \mu \mathrm{L}$ were applied per well and incubated for 1 hour. Because of the reducing environment of viable cells, this reagent is transformed and turns red, becoming highly fluorescent. The fluorescence was measured with a plate reader (Synergy BioTek, excitation $560 \mathrm{~nm}$, emission $590 \mathrm{~nm}$ ). After correction for background fluorescence, the results of the cells exposed to different concentrations of the photoinitiator were compared to each other and to the controls (non-stimulated cells). It was assumed that the metabolic activity of the control not exposed to photoinitiators is $100 \%$. A statistical evaluation of data was performed using software packages IBM SPSS Statistic 22 (SPSS Inc., Chicago, IL) and Excel 2013 (Microsoft Office). Results are presented as the average of repeated measurements 
\pm standard deviation (SD). After verifying the normal distribution and homogeneity of variance, a one-way analysis of variance was used to compare means of the samples. If a significant difference was observed ( $p<0.05)$, Bonferroni post hoc multiple comparison tests were performed to detect a significant difference between the samples.

\section{Evaluation of 2PI transmembrane migration}

MC3T3 cells were cultured in $\mu$-dishes $(35 \mathrm{~mm}$ diameter with glass bottom, high version, Ibidi $\mathrm{GmbH}$, Martinsried, Germany) until the glass bottom was covered with a nonconfluent monolayer of cells and then exposed to either E2CK or HAPI (as $0.1 \mathrm{mM}$ solutions in PBS). After $5 \mathrm{~min}$ of incubation time, the autofluorescence of the 2PIs was visualized by laser scanning microscopy (Zeiss Axio Observer Z1 with an LSM 700 unit including an objective Zeiss EC Plan Neofluar $20 \times / 0.5$, ZEN11 software for evaluation) using the $488 \mathrm{~nm}$ laser for excitation.

\section{Two-photon-polymerization (2PP) printing and assay of encapsulated cells}

The details of the $2 \mathrm{PP}$ microfabrication setup were reported previously. ${ }^{5}$ For the present work a femtosecond laser oscillator (MaiTai DeepSee by Spectra Physics) delivering $70 \mathrm{fs}$ pulses at around $800 \mathrm{~nm}$ was used. The beam was focused into the sample with a water-immersion microscopy objective $(32 \times / 0.85)$.

Methacrylamide-modified gelatin (Gel-MOD) with a degree of substitution of $72 \%$ used in this experiment was prepared in accordance with a previously reported protocol. ${ }^{26}$ Structures were written in a solution of $15 \%$ Gel-MOD in $\alpha M E M$ containing $1 \mathrm{mM}$ HAPI, $10 \mathrm{mM}$ MBCD and a cell density of 10 million cells per $1 \mathrm{~mL}$. The cell containing hydrogel precursor solution was applied to $\mu$-dishes ( $35 \mathrm{~mm}$ diameter with a glass bottom, high version, Ibidi GmbH, Martinsried, Germany) where the glass slide had been functionalized with methacrylate groups by cleaning and activating with a $4: 1$ mixture of conc. $\mathrm{H}_{2} \mathrm{SO}_{4}$ and $\mathrm{H}_{2} \mathrm{O}_{2}$ (30\% in water), and then using 3-(trimethoxysilyl) propyl methacrylate (Sigma Aldrich) according to the literature. ${ }^{27}$ The yin-yang structures were $2 \mathrm{PP}$-fabricated starting directly on the glass surface to ensure proper adhesion via covalent bonding between the methacrylated glass surface and the crosslinked hydrogel, operating the $2 \mathrm{PP}$ system at the following parameters: laser power after objective $60 \mathrm{~mW}$, scanning speed $100 \mathrm{~mm} \mathrm{~s}^{-1}$, hatch $0.5 \mu \mathrm{m}$, layer spacing $0.5 \mu \mathrm{m}$. The excess hydrogel precursor solution was removed after $2 \mathrm{PP}$ structuring by replacing the supernatant solution above the structures three times with fresh $\alpha M E M$, and incubating for $1 \mathrm{~h}$ at $37{ }^{\circ} \mathrm{C}$ in-between exchanges. The cells were stained by calcein-AM and propidium iodide (Life Technologies) as previously described, ${ }^{28} 24 \mathrm{~h}$ and 5 days after $2 \mathrm{PP}$ structuring. Hydrogel constructs and encapsulated cells were visualized by laser scanning microscopy using the $488 \mathrm{~nm}$ and $555 \mathrm{~nm}$ lasers for excitation (Zeiss LSM 700 and ZEN11 software for evaluation).

\section{Results and discussion}

\section{Synthesis and characterization}

Classical aldol condensation reactions under alkaline catalysis are a powerful and cost-efficient tool to build 2PI chromophore systems. ${ }^{16}$ Since primary amines (necessary for coupling to HA) are reactive towards aldehydes and ketones, the prevention of unwanted side-reactions during storage or the aldolcondensation reaction requires the use of a protective group. Thus (4-oxocyclohexyl)carbamic acid tert-butyl ester (Boc-CNK) was used as a starting material, and condensed with 4-(dimethylamino)benzaldehyde. This forms a dibenzylidene bischalcone of the quadrupolar $\mathrm{D}-\pi-\mathrm{A}-\pi-\mathrm{D}$ structure with dimethylamino-groups as strong electronic donors (D) and the carbonyl group as the acceptor (A), promoting a high 2PA cross section. ${ }^{16}$ The reactants are heated in ethanol in the presence of potassium hydroxide, leading to the precipitation of the protected 2PI Boc-MCNK with a yield of $70 \%$.

The deprotection was performed under mild conditions ${ }^{29}$ by stirring a suspension of Boc-MCNK in DCM vigorously with aqueous phosphoric acid and afforded the deprotected 2PI component MCNK with a yield of 95\%.

First coupling attempts between HA and MCNK achieved only low degrees of substitution (DS) of about $5 \%$ (determined from ${ }^{1} \mathrm{H}-\mathrm{NMR}$ measurements by comparing the integrals of the aromatic protons of MCNK with the $N$-acetyl protons of $\mathrm{HA}$ ), presumably because of the steric hindrance of the amino group on the cyclohexanone ring. Thus MCNK was amidated via a CDI based method ${ }^{30}$ by first reacting 4-(tert-butoxycarbonylamino)butyric acid (Boc-GABA-OH) with CDI to generate an activated carboxyl derivative, then adding freebase MCNK to form an amide bond and obtain Boc-MGABA (79\% yield). Subsequent deprotection by aqueous phosphoric acid ${ }^{29}$ afforded the 2PI component MGABA (94\% yield), providing a sterically less hindered amino group for attachment to HA.

For the final coupling step ${ }^{14,18-20}$ to generate the polymeric hyaluronan-based photoinitiator (HAPI), commercial sodium hyaluronate with an average molar weight of $1.6 \mathrm{MDa}$ was first converted to DMSO soluble tetrabutylammonium hyaluronate (TBA-HA) via acidification with an ion exchanger resin and subsequent neutralization with TBA-OH solution. Then a part of the carboxylate groups (the residual unsubstituted groups ensuring water solubility) was activated via reaction with CDI, and subsequently MGABA was added to form the polymeric 2PI HAPI. The reaction was quenched with excess sodium chloride solution and HAPI was precipitated and washed with acetone to remove unreacted MGABA. Removal of the low molecular weight HA as well as cytotoxic TBA-cations by dialysis and subsequent freeze-drying afforded ready to use HAPI. A schematic representation of the whole reaction sequence is depicted in Fig. 2.

Preliminary coupling experiments between HA and MGABA achieved DS up to $10 \%$, justifying the choice of the sterically more accessible amino group in comparison to MCNK. While HAPI prepared in this fashion was sufficiently water-soluble as a sodium salt, it could not be processed in $2 \mathrm{PP}$ structuring 
<smiles>CN(C)c1ccc(C=C2CC(NC(=O)NC3CC(=O)CCC3NC(=O)OC(C)(C)C)C(NC(=O)OC(C)(C)C)CC(=Cc3ccc(N(C)C)cc3)C2=O)cc1</smiles>

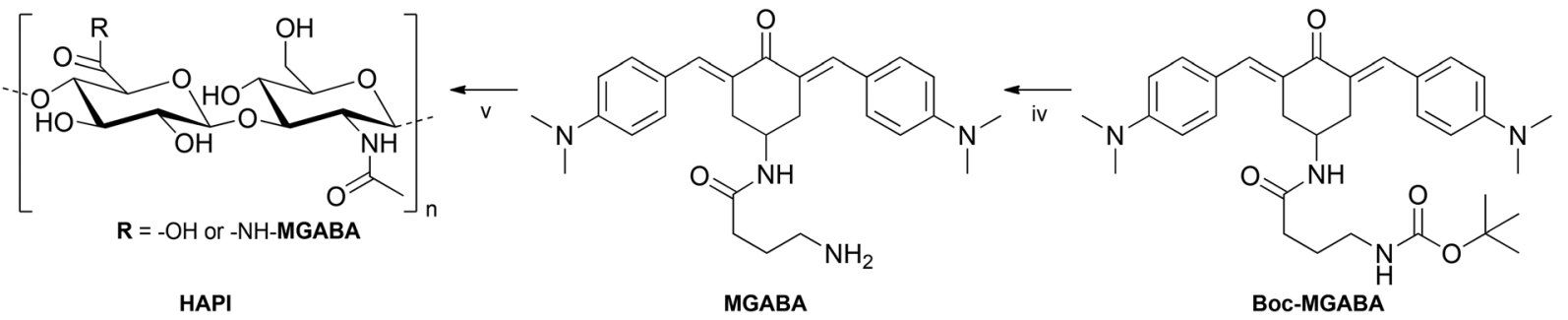

Fig. 2 Synthetic pathway to HAPI. Conditions (i) KOH, EtOH; (ii) aq. $\mathrm{H}_{3} \mathrm{PO}_{4}$, DCM; (iii) CDI, Boc-GABA-OH, DCM, (iv) aq. $\mathrm{H}_{3} \mathrm{PO}$, DCM; (v) TBA-hyaluronan, $\mathrm{CDI}, \mathrm{MeSO}_{3} \mathrm{OH}$, DMSO.

since a precipitation from the solution upon the addition of crosslinkable macromers like a modified gelatin (GelMod) ${ }^{5,26}$ occurred. As the first approach to improve the compatibility of HAPI with the macromers, the HAPI solubility was increased by using HA with a decreased molecular weight. While high molecular weight HA maintains homeostasis and potentially down-regulates inflammation, the generation of low molecular weight HA may act as an endogenous signal - likely mediated by cell surface receptors such as CD44 and TLR-4. ${ }^{31-33}$ Studies have demonstrated that low and very low molecular weight degradation products of HA may elicit various pro-inflammatory responses, such as a marked difference between $20 \mathrm{kDa}$ and $50 \mathrm{kDa} \mathrm{HA}$ on the upregulation of TNF- $\alpha$ expression in keratinocytes, ${ }^{34}$ or macrophages that undergo phenotypic changes dependent on the molecular weight of HA that correspond to either the (1) pro-inflammatory response for very low molecular weight (digest and $5 \mathrm{kDa}$ ) HA or (2) pro-resolving response for high molecular weight (800 and $3000 \mathrm{kDa}$ ) HA. ${ }^{33}$ Thus while the HAPI solubility is expected to be the highest for smaller HA fragments, a compromise had to be made in degradation to avoid the generation of higher amounts of HA with molecular weights below 20-50 kDa.

Acidic degradation of commercial 1.6 MDa sodium salt in solution at $\mathrm{pH} 1$ and $60^{\circ} \mathrm{C}$ for $24 \mathrm{~h}$, subsequent neutralization with TBA-OH and dialysis against deionized water to remove small HA fragments and excess TBA-Cl, afforded the TBA-salt of $\mathrm{HA}$ with a molecular weight of $50 \mathrm{kDa}$, which was converted to HAPI in the same fashion as the high molecular weight one.

\section{Photophysics}

The one-photon absorption (1PA) spectrum of HAPI resembles both the spectral bandshape (maximum around $470 \mathrm{~nm}$ ) and the maximum extinction coefficient (approx. $35 \times 10^{3}$ $\mathrm{M}^{-1} \mathrm{~cm}^{-1}$ ) of the reference 2PI (E2CK) almost to perfection
Table 1 Basic photophysical properties in PBS at $20^{\circ} \mathrm{C}$. $\lambda_{\text {abs, }}$ wavelength of 1PA maximum. $\varepsilon_{\max }$ molar extinction coefficient at 1PA maximum. $\phi$, fluorescence quantum yield

\begin{tabular}{lllllll}
\hline & $\begin{array}{l}\lambda_{\text {abs }} \\
{[\mathrm{nm}]}\end{array}$ & $\begin{array}{l}\varepsilon_{\max } \\
{\left[\mathrm{M}^{-1} \mathrm{~cm}^{-1}\right]}\end{array}$ & $\begin{array}{l}\lambda_{2 \mathrm{P}} \\
{[\mathrm{nm}]}\end{array}$ & $\begin{array}{l}\sigma^{(2)} \\
{[\mathrm{GM}]}\end{array}$ & $\begin{array}{l}\lambda_{\mathrm{em}} \\
{[\mathrm{nm}]}\end{array}$ & $\begin{array}{l}\phi \\
{\left[10^{-3}\right]}\end{array}$ \\
\hline E2CK & 471 & 35000 & 830 & 480 & $\sim 650$ & 2.5 \\
HAPI & 466 & 35000 & 840 & 400 & $\sim 650$ & 1.8
\end{tabular}

(see Table 1 and Fig. 3). The lowest energy absorption band exhibits a small shoulder at higher energies $(<400 \mathrm{~nm})$, which, in analogy to previous findings, ${ }^{16,17}$ may be attributed to a one-photon forbidden (two-photon allowed) transition that has its origin in the excitonic interaction of the two branches of the D- $\pi-\mathrm{A}-\pi-\mathrm{D}$ system. ${ }^{35}$ The fluorescence of E2CK and HAPI peaks around $650 \mathrm{~nm}$, with fluorescence quantum yields in PBS being very low (around $0.2 \%$ ). The associated fluorescence lifetimes are significantly below the time-resolution of our set-up ( $<100 \mathrm{ps})$. Whether this low emission efficiency and fast deactivation of the singlet state has its origin in an

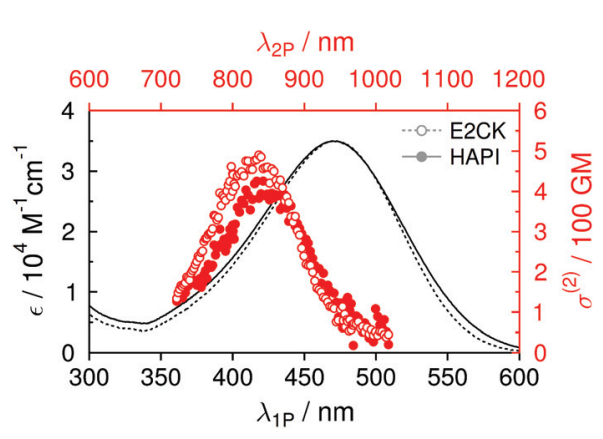

Fig. 3 One-photon (black) and two-photon (red) absorption spectra of HAPI and E2CK in PBS. 
ultrafast internal conversion channel back to the ground state or an enhanced intersystem crossing channel to the triplet state is currently being investigated using ultrafast transient absorption spectroscopy.

Two-photon (2P) induced fluorescence was used to record the corresponding two-photon excitation spectra and cross sections. Again, HAPI shows almost identical behavior to E2CK, with the 2PA maximum being around 830-840 $\mathrm{nm}$ and maximum 2PA cross-section values in the range of approx. 400-500 GM (see Table 1 and Fig. 3). The slightly lower maximum 2PA cross section of HAPI compared to E2CK could be the result of slightly different degrees of planarity of the 2PI chromophores (different substituents on the amino-donor groups and on the central cyclohexanone ring) as has been previously reported for similar derivatives. ${ }^{16}$ However, it is worth noting that this observed difference is also in the same order of magnitude as the potential error related to the very low fluorescence quantum yields as well as the error related to the NMR-determination of HAPI's DS, both of which affect the calculated $2 \mathrm{P}$ cross sections. The fact that the strong $2 \mathrm{P}$ transition shows up at lower wavelengths is in line with the above mentioned excitonic interaction of the two branches of the $D-\pi-A-\pi-D$ system and has been extensively described ${ }^{36,37}$ and observed in the literature for structurally similar systems. ${ }^{17}$

\section{PI transmembrane migration}

To investigate the effect of the covalent linking of the 2PI to HA on transmembrane migration from the ECM to the cytosol, MC3T3 cells were exposed to solutions of either HAPI or E2CK. The distribution of the 2PIs was then visualized by laser scanning microscopy (LSM) imaging, taking advantage of the autofluorescence of the 2PI chromophores. HAPI does not readily enter the cells and exhibits a weak fluorescence (Fig. 4(a), brightness digitally enhanced) in the surrounding medium, the cells themselves appearing comparatively dark against this background fluorescence. In the case of E2CK the picture is reversed (see Fig. 4(b)), with the cells readily taking up the 2PI and various structures inside the cells appearing brightly stained. This provides a strong indication that the transmem-

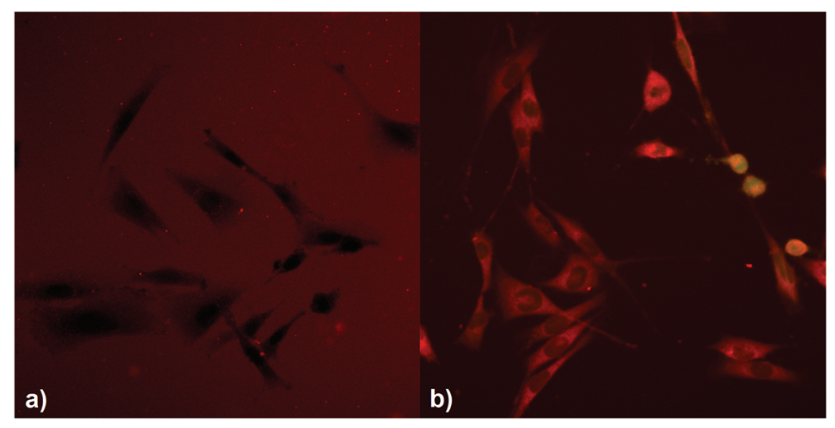

Fig. 4 LSM images visualizing the autofluorescence of HAPI (a) and E2CK (b) around and into MC3T3 cells, indicating their different transmembrane migration behavior. The brightness of HAPI-image had to be digitally enhanced compared to E2CK images for better visibility of dark cells against a brighter fluorescence background. brane migration of the $2 \mathrm{PI}$ is effectively hindered by covalent linkage to HA.

\section{Cytotoxicity assay}

During the 2PP sample preparation and printing process, the cells come into prolonged contact with the material containing dissolved 2PI, even if they are destined to be trapped in the cavities of a structure and are thus not directly exposed to laser radiation and laser-induced radicals. Thus besides phototoxicity, the cytocompatibility of the 2PIs without excitation by 2PA is also of interest. MC3T3 cells were exposed to the $\alpha \mathrm{MEM}$ cell culture medium containing either HAPI or the water-soluble 2PI reference $\mathbf{E} 2 \mathbf{C K}^{6}$ at various concentrations. After an exposure time of 5 hours, a representative time frame for the 2PP manufacturing even of relatively large structures, the metabolic activity of cells was evaluated with a PrestoBlue assay. While a comparison of HAPI with a control sample incubated under the same conditions but without 2PI showed no statistically significant difference, in the concentration range from $0.5 \mathrm{mM}-2 \mathrm{mM}$ the metabolic activity for E2CK was decreased versus the control by $40 \pm 9 \%$ to $49 \pm 9 \%$, indicating a significant cytotoxicity of the reference compound but not HAPI (see Fig. 5).

\section{PP encapsulation of cells}

To examine the functionality of the HAPI in its dedicated application of living cell encapsulation, 3D polymeric hydrogel structures were printed via $2 \mathrm{PP}$ in a cell suspension containing dissolved HAPI and GelMod.

While high molecular weight (1.6 MDa HA) HAPI was soluble in $\alpha$ MEM cell culture medium at the desired concentrations, upon mixing with GelMod solutions a phase separation occurred and HAPI formed a dense, deeply red gel-like precipitate, depriving the supernatant solution of the photoinitiator. An increase in the solubility was first attempted by using degraded lower molecular weight HA (50 kDa) as the starting material. This measure increased the compatibility significantly, but proved insufficient, so further stabilization of the solvation of the HAPI chains was attempted by adding methyl- $\beta$-cyclodextrin (MBCD), which is expected to form inclusion complexes with the apolar parts of

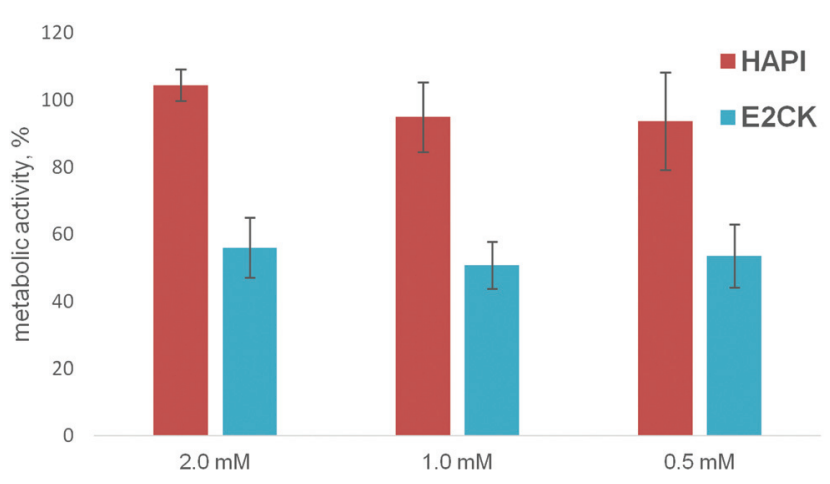

Fig. 5 Influence of different concentrations of HAPI and E2CK on the metabolic activity of MC3T3-E1 cells after 5 hours (PrestoBlue cell viability test). All values are presented as $\%$ of the positive untreated control. 


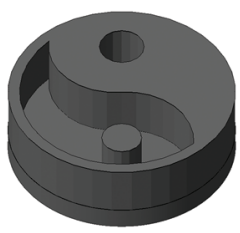

a)
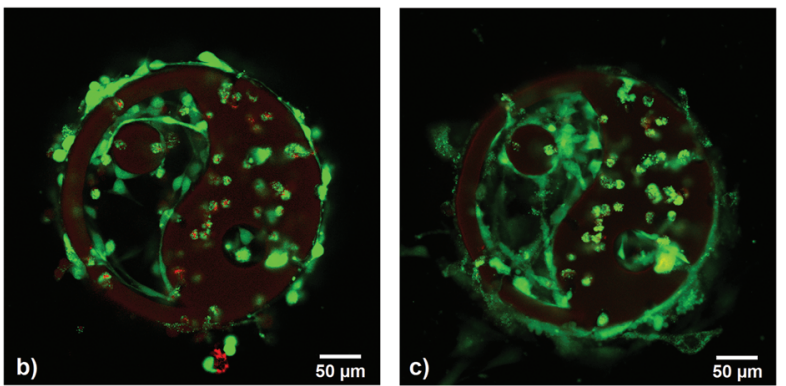

Fig. 6 (a) CAD model of the yin-yang structure (upside down for better visibility of the cavities, top layer in the picture is joined to the glass substrate), (b) encapsulated MC3T3 $24 \mathrm{~h}$ after 2PP structuring - cells in the cavity are stretching, encapsulated cells show a round morphology, (c) same structure 5 days after 2PP - cells in the cavity are proliferating, encapsulated cells are viable but round, possibly due to physical confinement.

the bound MGABA, thus weakening interactions like $\pi-\pi$ stacking of the photoinitiator component. At a concentration of $10 \mathrm{mM}$ MBCD was able to stabilize mixtures containing 15\% GelMod and $1 \mathrm{mM}$ low molecular weight HAPI so that 2PP structuring was successful. It should be noted that the literature ${ }^{38}$ suggests the cytotoxicity of MBCD at the required concentrations and our preliminary tests showed a greater reduction of the metabolic activity by $10 \mathrm{mM}$ MBCD alone than by $2 \mathrm{mM}$ E2CK. However in the case of actual 2PP encapsulation, cell survival was excellent (see Fig. 6) likely because MBCD predominantly binds to the large amount of GelMod present in the hydrogel precursor formulations, and thus does not interfere with the cells.

For 2PP encapsulation of live cells, a 3D yin-yang structure was written into a suspension of MC3T3 cells in $\alpha$ MEM cell culture medium containing 15\% GelMod, $1 \mathrm{mM}$ HAPI and $10 \mathrm{mM}$ MBCD. The yin-yang structure (see Fig. 6) allows for an easy side-by-side comparison of cells that have been exposed to the laser and are encapsulated in the hydrogel and cells that have not been exposed but are trapped in the medium-filled cavity of the structure. ${ }^{5}$

Cell viability was assayed $24 \mathrm{~h}$ and 5 days after printing by live/dead-staining and LSM imaging, showing live cells in green and dead cells in red. The hydrogel itself also appears stained red due to the autofluorescence of residual 2PI. Throughout the examined period, cell survival was excellent, both in the polymerized parts and the cavities of the structure. After 5 days, the cells in the cavity had a stretched morphology and proliferated, while encapsulated cells were still alive but showed a round morphology, possibly due to physical confinement within the surrounding GelMod matrix (see Fig. 6).

\section{Conclusions}

The two-photon initiator precursor MGABA was developed, containing a donor- $\pi$-acceptor- $\pi$-donor structure motif for efficient two-photon absorption and a sterically accessible primary amino group to allow for high degrees of substitution in subsequent modification reactions on hyaluronan. A novel hyaluronan-based polymeric two-photon initiator (HAPI) was prepared and characterized.
Laser scanning microscopy of cells incubated with either HAPI or the reference small molecule 2PI E2CK indicated that the macromolecular nature of HAPI indeed hinders 2PI transmembrane migration effectively.

The assay of cytotoxicity independent of two-photon excitation proved a superior biocompatibility of HAPI compared to the reference water-soluble two-photon initiator E2CK. 3D hydrogel structures containing living cells were successfully produced by the 2PP crosslinking of GelMod with HAPI in the presence of methyl- $\beta$-cyclodextrin as an additive to stabilize the hydrogel precursor solutions. The samples were followed up for at least 5 days using a live/dead-staining assay confirming the viability of the cells over this period. These results indicate the low phototoxicity and high efficiency of HAPI, as evidenced by a high scanning speed $\left(100 \mathrm{~mm} \mathrm{~s}^{-1}\right)$ during the $2 \mathrm{PP}$ process. While optimization of the solubility behavior and further investigation of the relationship between the structure of HAPI and two-photon initiation activity are desirable, the system shows excellent biocompatibility and is a promising basis for further developments of the encapsulation of live cells by two-photon induced polymerization.

\section{Acknowledgements}

The authors acknowledge the financial support by the European Research Council (Starting Grant-307701, A. O.), the Austrian Science Fund (FWF, Project P27555) and the Université de Genève. We would also like to acknowledge the support of Prof. Dr Sandra Van Vlierberghe and Prof. Dr Peter Dubruel (Polymer Chemistry and Biomaterials Group, Ghent University, Belgium) for providing methacrylated gelatin (GelMod), and Prof. Dr Oscar Hoffmann (Department of Pharmacology and Toxicology, University of Vienna, Austria) for providing the cells for biological experiments.

\section{References}

1 M. Rumi, S. Barlow, J. Wang, J. W. Perry and S. R. Marder, Two-photon absorbing materials and two-photon-induced 
chemistry, Adv. Polym. Sci., 2008, 213(Photoresponsive Polymers I), 1-95.

2 A. Ovsianikov, V. Mironov, J. Stampf and R. Liska, Engineering 3D cell-culture matrices: multiphoton processing technologies for biological and tissue engineering applications, Expert Rev. Med. Devices, 2012, 9(6), 613-633.

3 M. Bokhari, R. J. Carnachan, N. R. Cameron and S. A. Przyborski, Culture of HepG2 liver cells on three dimensional polystyrene scaffolds enhances cell structure and function during toxicological challenge, J. Anat., 2007, 211(4), 567-576.

4 E. Cukierman, R. Pankov, D. R. Stevens and K. M. Yamada, Taking cell-matrix adhesions to the third dimension, Science, 2001, 294(5547), 1708-1712.

5 A. Ovsianikov, S. Mühleder, J. Torgersen, Z. Li, X.-H. Qin, S. Van Vlierberghe, P. Dubruel, W. Holnthoner, H. Redl, R. Liska and J. Stampfl, Laser Photofabrication of CellContaining Hydrogel Constructs, Langmuir, 2014, 30(13), 3787-3794.

6 Z. Li, J. Torgersen, A. Ajami, S. Muehleder, X. Qin, W. Husinsky, W. Holnthoner, A. Ovsianikov, J. Stampfl and R. Liska, Initiation efficiency and cytotoxicity of novel water-soluble two-photon photoinitiators for direct 3D microfabrication of hydrogels, RSC Adv., 2013, 3(36), 15939-15946.

7 D. Decuyper-Debergh, J. Piette, C. Laurent and A. Van de Vorst, Cytotoxic and genotoxic effects of extracellular generated singlet oxygen in human lymphocytes in vitro, Mutat. Res. Lett., 1989, 225(1-2), 11-14.

8 J. G. Parker, Optical monitoring of the generation of singlet oxygen during photodynamic treatment of tumors, Johns Hopkins APL Tech. Dig., 1990, 11(1-2), 185-190.

9 D. Vigetti, E. Karousou, M. Viola, S. Deleonibus, G. De Luca and A. Passi, Hyaluronan: Biosynthesis and signaling, Biochim. Biophys. Acta, Gen. Subj., 2014, 1840(8), 2452-2459.

10 J. A. Burdick and G. D. Prestwich, Hyaluronic Acid Hydrogels for Biomedical Applications, Adv. Mater., 2011, 23(12), H41-H56.

11 M. N. Collins and C. Birkinshaw, Hyaluronic acid based scaffolds for tissue engineering-A review, Carbohydr. Polym., 2013, 92(2), 1262-1279.

12 C. B. Highley, G. D. Prestwich and J. A. Burdick, Recent advances in hyaluronic acid hydrogels for biomedical applications, Curr. Opin. Biotechnol., 2016, 40, 35-40.

13 C. E. Schante, G. Zuber, C. Herlin and T. F. Vandamme, Chemical modifications of hyaluronic acid for the synthesis of derivatives for a broad range of biomedical applications, Carbohydr. Polym., 2011, 85(3), 469-489.

14 D. Bellini and A. Topai, Preparation and use of hyaluronic acid amides or other derivatives, Fidia Advanced Biopolymers S.r.l., Italy, 2000, p. 36.

15 J. N. Mehrishi and J. Bauer, Electrophoresis of cells and the biological relevance of surface charge, Electrophoresis, 2002, 23(13), 1984-1994.

16 Z. Li, N. Pucher, K. Cicha, J. Torgersen, S. C. Ligon, A. Ajami, W. Husinsky, A. Rosspeintner, E. Vauthey,
S. Naumov, T. Scherzer, J. Stampfl and R. Liska, A Straightforward Synthesis and Structure-Activity Relationship of Highly Efficient Initiators for TwoPhoton Polymerization, Macromolecules, 2013, 46(2), 352361.

17 Q. Zou, Y. Zhao, N. S. Makarov, J. Campo, H. Yuan, D.-C. Fang, J. W. Perry and F. Wu, Effect of alicyclic ring size on the photophysical and photochemical properties of bis(arylidene)cycloalkanone compounds, Phys. Chem. Chem. Phys., 2012, 14(33), 11743-11752.

18 A. Borzacchiello, L. Mayol, A. Schiavinato and L. Ambrosio, Effect of hyaluronic acid amide derivative on equine synovial fluid viscoelasticity, J. Biomed. Mater. Res., Part A, 2010, 92A(3), 1162-1170.

19 M. D'Este, M. Alini and D. Eglin, Single step synthesis and characterization of thermoresponsive hyaluronan hydrogels, Carbohydr. Polym., 2012, 90(3), 1378-1385.

20 M. Pavan, D. Galesso, G. Menon, D. Renier and C. Guarise, Hyaluronan derivatives: Alkyl chain length boosts viscoelastic behavior to depolymerization, Carbohydr. Polym., 2013, 97(2), 321-326.

21 J. A. Gardecki and M. Maroncelli, Set of Secondary Emission Standards for Calibration of the Spectral Responsivity in Emission Spectroscopy, Appl. Spectrosc., 1998, 52(9), 1179-1189.

22 P.-A. Muller, C. Högemann, X. Allonas, P. Jacques and E. Vauthey, Deuterium isotope effect on the charge recombination dynamics of contact ion pairs formed by electrontransfer quenching in acetonitrile, Chem. Phys. Lett., 2000, 326(3-4), 321-327.

23 N. S. Makarov, M. Drobizhev and A. Rebane, Two-photon absorption standards in the 550-1600 nm excitation wavelength range, Opt. Express, 2008, 16(6), 4029-4047.

24 H. Ceymann, A. Rosspeintner, M. H. Schreck, C. Mutzel, A. Stoy, E. Vauthey and C. Lambert, Cooperative enhancement versus additivity of two-photon-absorption cross sections in linear and branched squaraine superchromophores, Phys. Chem. Chem. Phys., 2016, 18(24), 1640416413.

25 S. de Reguardati, J. Pahapill, A. Mikhailov, Y. Stepanenko and A. Rebane, High-accuracy reference standards for twophoton absorption in the 680-1050 $\mathrm{nm}$ wavelength range, Opt. Express, 2016, 24(8), 9053-9066.

26 A. Ovsianikov, A. Deiwick, S. Van Vlierberghe, P. Dubruel, L. Möller, G. Dräger and B. Chichkov, Laser Fabrication of Three-Dimensional CAD Scaffolds from Photosensitive Gelatin for Applications in Tissue Engineering, Biomacromolecules, 2011, 12(4), 851-858.

$27 \mathrm{H}$. Garoff and W. Ansorge, Improvements of DNA sequencing gels, Anal. Biochem., 1981, 115(2), 450-457.

28 M. Markovic, J. Van Hoorick, K. Hölzl, M. Tromayer, P. Gruber, S. Nürnberger, P. Dubruel, S. Van Vlierberghe, R. Liska and A. Ovsianikov, Hybrid Tissue Engineering Scaffolds by Combination of Three-Dimensional Printing and Cell Photoencapsulation, J. Nanotechnol. Eng. Med., 2015, 6(2), 021001-021001. 
29 B. Li, M. Berliner, R. Buzon, C. K. F. Chiu, S. T. Colgan, T. Kaneko, N. Keene, W. Kissel, T. Le, K. R. Leeman, B. Marquez, R. Morris, L. Newell, S. Wunderwald, M. Witt, J. Weaver, Z. Zhang and Z. Zhang, Aqueous phosphoric acid as a mild reagent for deprotection of tert-butyl carbamates, esters, and ethers, J. Org. Chem., 2006, 71(24), 90459050 .

30 I. Smukste and D. B. Smithrud, Structure-Function Relationship of Amino Acid-[2]Rotaxanes, J. Org. Chem., 2003, 68(7), 2547-2558.

31 M. Farwick, P. Lersch and G. Strutz, Low Molecular Weight Hyaluronic Acid: Its Effects on Epidermal Gene Expression \& Skin Ageing, Verlag für chemische Industrie, Augsburg, Germany, 2008, vol. 134.

32 G. M. Campo, A. Avenoso, G. Nastasi, A. Micali, V. Prestipino, M. Vaccaro, A. D’Ascola, A. Calatroni and S. Campo, Hyaluronan reduces inflammation in experimental arthritis by modulating TLR-2 and TLR-4 cartilage expression, Biochim. Biophys. Acta, Mol. Basis Dis., 2011, 1812(9), 1170-1181.

33 J. E. Rayahin, J. S. Buhrman, Y. Zhang, T. J. Koh and R. A. Gemeinhart, High and Low Molecular Weight Hyaluronic Acid Differentially Influence Macrophage Activation, ACS Biomater. Sci. Eng., 2015, 1(7), 481-493.
34 M. Farwick, G. Gauglitz, T. Pavicic, T. Köhler, M. Wegmann, K. Schwach-Abdellaoui, B. Malle, V. Tarabin, G. Schmitz and H. C. Korting, Fifty-kDa Hyaluronic Acid Upregulates Some Epidermal Genes without Changing TNF- $\alpha$ Expression in Reconstituted Epidermis, Skin Pharmacol. Physiol., 2011, 24(4), 210-217.

35 C. Katan, S. Tretiak, M. H. V. Werts, A. J. Bain, R. J. Marsh, N. Leonczek, N. Nicolaou, E. Badaeva, O. Mongin and M. Blanchard-Desce, Two-Photon Transitions in Quadrupolar and Branched Chromophores: Experiment and Theory, J. Phys. Chem. B, 2007, 111(32), 9468-9483.

36 C. Katan, F. Terenziani, C. Le Droumaguet, O. Mongin, M. H. V. Werts, S. Tretiak and M. Blanchard-Desce, Branching of dipolar chromophores: effects on linear and nonlinear optical properties, 2005.

37 F. Terenziani, A. Painelli, C. Katan, M. Charlot and M. Blanchard-Desce, Charge Instability in Quadrupolar Chromophores: Symmetry Breaking and Solvatochromism, J. Am. Chem. Soc., 2006, 128(49), 15742-15755.

38 Y.-A. Choi, B. R. Chin, D. H. Rhee, H.-G. Choi, H.-W. Chang, J.-H. Kim and S.-H. Baek, Methyl-[beta]-cyclodextrin inhibits cell growth and cell cycle arrest via a prostaglandin E(2) independent pathway, Exp. Mol. Med., 2004, 36, 78-84. 